\title{
Inflammation, Oxidative Stress and Atherosclerosis in Chronic Renal Failure Patients
}

\author{
Hosny A. Hassan*, Mona A.H. EL-Baz*, Mohammed A. Sobh**, \\ Hossam Abo Zaid***, Taha S. Mostafa* \\ Medical Biochemistry*, Internal Medicine** and Radiology, ${ }^{* * *}$ \\ Departments, Faculty of Medicine. Assuit University
}

\begin{abstract}
Background: Accelerated atherosclerosis is the major cause of mortality in patients on chronic hemodialysis (HD). Inflammation, increased oxidative stress and endothelial activation or dysfunction might be the major factors leading to high cardiovascular mortality rate in HD patients. Also, C667T mutation of methylenetetrahydrofolate reductase (MTHFR) might be associated with accelerated atherosclerosis. Aim: The present study was designed to clarify the role of inflammation, oxidative stress parameters, endothelial activation or dysfunction and genotyping of MTHFR enzyme which affect the level of homocysteine and their relation to carotid artery intima-media thickness (CIMT) as indicators of atherosclerosis. Subjects \& Methods: 44 chronic hemodialysis (HD) patients and 40 healthy subjects were included in the study. Serum highly sensitive $C$ reactive protein (hs-CRP) and IL-6 were measured as inflammatory markers, soluble vascular cell adhesion molecule-1 (sVCAM-1) was measured as a marker of endothelial activation and dysfunction. Serum thiobarbituric acid reactive substances (TBARS), total nitric oxide (NO), total peroxides (TP), total antioxidant capacity (TAC) and oxidative stress index (OSI) levels were determined as oxidative stress markers. Common carotid intima media thickness (CC-IMT) was assessed by carotid artery ultrasonography, genotyping of MTHFR enzyme which affect the level of homocysteine was analyzed by PCR -RFLIP technique. Results: Chronic HD patients had elevated levels of inflammatory markers (hs-CRP and IL-6), enhanced endothelial activation or dysfunction demonstrated by elevated VCAM-1 as compared by healthy controls. Also, they had enhanced oxidative stress indicated by the higher levels of NO, TBARS, TP, OSI and lower levels of TAC as compared to controls. Hemodialysis patients had significantly higher CC-IMT levels. There is a significant positive correlation between inflammatory cytokines (hs-CRP and IL-6), and each of TBARS, total NO, TP and OSI with CC-IMT Also, the previous parameters negatively correlated with TAC. There is no significant difference in the genotype of C667T MTHFR between patients and controls, but that mutation especially the TT genotype is associated with development of atherosclerosis as indicated by the increase of CCIMT.
\end{abstract}




\section{INTRODUCTION}

Chronic renal failure is a common health problem allover the world and has its implications on both the quality of life and economic state of the patients. The number of patients with end-stage renal disease (ESRD) treated with renal replacement therapy by dialysis or transplantation is rapidly increasing worldwide ${ }^{(\mathbf{1})}$. There is a trend for rise in number of patients with ESRD in Europe that is similar to that of the USA ${ }^{(2)}$.

Despite rapid improvement in dialysis technology, ESRD patients undergoing maintenance HD, experience lower quality of life, significantly greater morbidity, higher hospitalization rates, and higher mortality compared with the general population ${ }^{(3)}$. Although some dialysis patients live longer than 5 to 10 years and are able to work and contribute to the society in which they live, others are far poorly and die within 2 to 3 yrs. In addition to mortality, another issue surrounding ESRD is a rapidly aging dialysis population ${ }^{(3)}$. The main cause of the increased mortality in those patients is cardiovascular disease (CVD). Although the established cardiovascular risk factors such as diabetes, hypertension, dyslipidemia, and smoking are common in ESRD patients, they can only, in part, explain the high prevalence of CVD observed in that patients group ${ }^{(4)}$. So, CVD accounts for a premature death in more than $50 \%$ of patients from Western Europe and North America undergoing regular dialysis. Actually, the risk for CVD in a 30 -yrs-old ESRD patient is similar to the calculated risk of a 70 to 80 -yrs-old subject from the non renal population $^{(5)}$.

Nurcan et al. (6) showed the presence of chronic low grade inflammation in ESRD patients on maintenance hemodialysis, and considered hemodialysis a state of chronic inflammation. In this state, the pro-inflammatory molecules play an important role in endothelial dysfunction, providing a link between inflammation, atherogenesis and excessive cardiovascular morbidity and mortality in ESRD patients ${ }^{(6)}$.

Patients with chronic renal failure on hemodialysis are constantly exposed to oxidative stress which is mostly attributed to the imbalance between oxidants and antioxidants due to the diffusion of hydrophilic compounds to the dialysate.

A common mutation in methylenetetrahydrofolate reductase, $(667 \mathrm{C} \rightarrow \mathrm{T})$ that is associated with the thermolabile MTHFR enzyme leads to decreased activity of that enzyme ${ }^{(7)}$. A thermolabile variant of MTHFR, with reduced specific activity has been identified in which a substitution of cytosine (C) by thymine (T) at nucleotide 677 of the MTHFR gene. This converts an alanine to a valine residue that was responsible for the thermolability of MTHFR ${ }^{(7)}$. It was suggested that the homozygosity for the MTHFR C677T polymorphism was associated with an increased risk of coronary heart disease. Also, the study pointed at a moderate increase in plasma homocysteine and the risk of CVD in patients with MTHFR C677T mutation ${ }^{(7)}$. 
Common carotid intima media thickness (CC-IMT) as measured by ultrasonography represents a marker of structural atherosclerosis. Increased CC-IMT was shown to be correlated with the $\mathrm{CV}$ risk and severity of coronary atherosclerosis ${ }^{(\mathbf{8 , 9})}$. Increased CC-IMT is considered as an early phase of atherosclerosis and might be seen even in patients with mild hypertension and normal serum cholesterol (10). Assessment of $\mathrm{CC}$ IMT using high-resolution B-mode ultrasonography is a reliable, reproducible and non-invasive method for detecting and monitoring the progression of atherosclerosis ${ }^{(11)}$.

\section{SUBJECTS \& METHODS}

The current study included 84 persons divided into two groups: group I: 44 chronic renal patients on hemodialysis. Inclusion criteria: aged range $35-50$ years. All are clinically stable and free of active infections (no fever, no common cold, no pneumonia etc). Exclusion criteria: Patients with diabetes mellitus, liver diseases, autoimmune diseases, or malignancies were excluded in order to avoid the possible effects of these co-morbid conditions on the studied parameters. None of the patients were receiving antibiotics, corticosteroids, or cytotoxic drugs at the time of the study. Group II (Control group): 40 completely healthy persons and their kidney function tests were normal. Patients and controls were participated in the study after giving their informed consent.

Sample collections:

Blood samples from the HD patients were taken immediately before the beginning of a 4-hours routine HD session. Blood sample was divided to 3 parts, one part was taken on EDTA for genomic analysis, one part was taken on heparin for determination of plasma TP and TAC and the rest of sample was used for determination of NO, TBARS, IL-6 and hs-CRP and sVCAM-1. Second and third tubes were immediately centrifuged $(3000 \mathrm{rpm}$ for 10 minutes), serum, plasma separated and stored at $-70{ }^{\circ} \mathrm{C}$ until assay.

\section{Biochemical Analysis:}

Interleukin-6 was measured by AviBion Human IL-6 ELISA kit. Catalogue number IL06001, manufactured by Orgenium Laboratories, Finland (12). High Sensitivity CRP (hs-CRP) was measured by CRP ELISA kit. Catalogue number 3125-300 manufactured by Monobind Inc. USA (13). Serum levels of the circulating adhesion molecules VCAM-1 were measured using BioSource Immunoassay Human Soluble Vascular Cell Adhesion Molecule-1 (Hu sVCAM-1) ELISA kit. Catalogue number \#KHT0602/KHT0601 manufactured by BioSource International, Inc., Belgium (14). Thiobarbituric acid reactive substances were measured by chemical method according to Uchiama and Mihara ${ }^{(15)}$. Total NO levels were measured by chemical method of Van Bezooijen et al., ${ }^{(16)}$. Total peroxides (TP) were assayed according to Harma et al. ${ }^{(17)}$. Total antioxidant capacity (TAC) was assayed by TAC-chemical Kit. Catalogue number GR $25 \quad 10$ manufactured by Biodiagnostic, Egypt $^{(18)}$. Oxidative stress index (OSI) 
is the percent ratio of the total peroxide content to the total antioxidant capacity (TAC) calculated according to the following equation (17). OSI = (Total peroxide, $\mathrm{mM} / \mathrm{L}) /(\mathrm{TAC}, \quad \mathrm{mM} \quad$ Trolox equivalent/L) X 100.

\section{Genomic analysis:}

The C677T mutation in the MTHFR gene was analyzed by the PCR of genomic DNA using the method described by Frosst et al. ${ }^{(19)}$. Genomic DNA was extracted from the whole blood using commercially available Qiagen DNA extraction kit. DNA samples were kept at $-80^{\circ} \mathrm{C}$ till analyzed by PCR-RFLP. The C677T MTHFR gene mutation was detected by PCR-RFLP analysis using Hinf I restriction analysis of a 198-bp polymerase chain reaction. The oligonucleotide primers, sense strand: 5'-TGA AGG AGA AGG TGT CTG CGG GA-3 and anti-sense strand: 5'AGG ACG GTG CGG TGA GAG TG-3', were used to amplify the exon 4 of MTHFR gene. A $25 \mu 1$ PCR reaction mixture consisted of $5 \mu \mathrm{l}$ of genomic DNA, Promega master mix and $2 \mu \mathrm{l}(5 \mathrm{pmol})$ of each primer PCR reaction were put in a $0.6 \mathrm{ml}$ microcentrifuge tube and run in a Gene Amp, thermocycler (Biorad, USA). Mutation polymorphism was detected by RFLP analysis technique, and DNA fragments were separated by electrophoresis in a $4 \%$ agarose gel followed by ethidium bromide staining and UV illumination allowed detection of mutated alleles.

\section{Radiological-measurements:}

Carotid atherosclerosis was assayed by (carotid Doppler) ultrasonographically. Measurement of intima-media thickness (IMT) of the carotid artery was done using a computed color duplex sonography system (Acuson $128 \times \mathrm{P}$ ) using real time $\mathrm{B}$ mode. Examination was performed with a trasducer 7.5 MHZ linear array or $5 \mathrm{MHZ}$ linear trasducer. Measurements of IMT were made on the common carotid arteries (CCA), $2 \mathrm{~cm}$ below its bifurcation. The examination was done for the right and left common carotid arteries and the mean values of the two sites were used in the analysis.

\section{Statistical methods:}

The results were statistically analyzed using computer database (Graph pad prism version 5). Data comparisons were performed by using student unpaired " $t$ " test to compare between patients and controls. Pearson correlation was used to indicate the relationship between levels of variables, the levels of significance were accepted with $\mathrm{P}<$ 0.05 and the results were presented in tables as mean $\pm \mathrm{SD}$.

\section{RESULTS}

Clinical and demographic characteristics of the patients and controls are given in table 1 . There were no significant differences in age and gender among the two groups. Body mass index (BMI) was significantly lower, while systolic and diastolic blood pressure were significantly higher in HD patients compared to controls $\mathrm{P}<0.0001$ for each.

The measured inflammatory markers are shown in table 2. The serum levels of hs-CRP and IL- 6 were significantly higher in hemodialysis 
group as compared to control group $\mathrm{P}<0.0001$ for each.

Oxidant and antioxidant markers are shown in table 3 . The serum levels of The serum levels of TBARS, NO, $\mathrm{TP}$, and OSI were significantly higher in hemodialysis group as compared to control group $(\mathrm{P}<0.0001$ for each). On the other hand, the plasma levels of TAC was significantly lower in hemodialysis patients than controls $\mathrm{P}<0.0001$.

Markers of endothelial dysfunction and atherosclerosis are shown in table 4 . The serum levels of CC-IMT and SVCAM 1 were significantly higher in hemodialysis group as compared to control group $(\mathrm{P}<0.0001$ for each.

After digestion with restriction enzyme the replacement of $\mathrm{C}$ by $\mathrm{T}$ mutation lead to creation of restriction site for Hinf I that lead to 3 genotypes figure (1), the homozygous normal wild type CC showed a single band at the 198 base pair (bp). The heterozygote CT showed two bands, one at the 198 and the second at 175 bp. The homozygote TT showed one band at the $175 \mathrm{bp}$.

MTHFR genotyping data are shown in table 5. There is no significant difference in the number or percentage of CC (wild type), or mutated CT (heterozygous), TT (homozygous), or the total mutation among the hemodialysis and control groups respectively. Also, there is no significant difference between the two groups as regard the frequency of $\mathrm{C}$ and $\mathrm{T}$ alleles.
The different parameters in different genotypes are shown in table 6. The levels of hs-CRP, IL-6, VCAM-1, and CC-IMT were significantly higher in TT genotype than the wild type $\mathrm{CC}$ with $\mathrm{p}$ value $0.028,0.039,0.044,0.029$ and 0.012 respectively. However, there are no significant differences as regard these parameters between TT and CT or CT and CC. Also, there are no difference between the 3 genotypes as regard NO, TP, TAC and OSI.

The different parameters in mutated group and non mutated group are shown in table 7 . The levels of hsCRP, IL-6, VCAM-1,CC-IMT, TBARS and TP were significantly higher in the mutated than non mutated groups with $\mathrm{P}$ values of $0.023,0.030,0.002,0.014,0.006$ and 0.0192 respectively. However, there is no significant difference between the two groups as regards, NO, TAC, OSI and BMI.

Matrix of correlation coefficient between the different parameters in hemodialysis is shown in table 8 . HsCRP level was positively correlated with IL-6, VCAM-1, TBARS, TP, OSI and CC-IMT $\mathrm{p}<0.05$ for each. IL6 level was positively correlated with VCAM-1, TBARS, TP, OSI and CCIMT $\mathrm{p}<0.05$ for each. There is a positive correlation between VCAM-1 and CC-IMT $\mathrm{p}<0.05$. CC-IMT positively correlated with TBARS, NO, TP and OSI $p<0.05$ for each. CCIMT is inversely correlated with TAC $\mathrm{p}<0.05$. 
Table (1): Clinical and demographic data of the investigated subjects

\begin{tabular}{l|lll}
\hline Item & $\begin{array}{l}\text { Group I } \\
(n=44)\end{array}$ & $\begin{array}{l}\text { Group II } \\
\text { (Controls) }(n=40)\end{array}$ & P-value \\
\hline $\begin{array}{l}\text { Age (years) } \\
\text { Mean } \pm \text { SD }\end{array}$ & $36.07 \pm 9.422$ & $33.5 \pm 7.5$ & $\mathrm{NS}$ \\
$\quad \begin{array}{l}\text { Sex } \\
\text { Male/female }\end{array}$ & $32 / 12$ & $24 / 16$ & $\mathrm{NS}$ \\
$\quad \begin{array}{l}\text { BMI (Kg/m²) } \\
\quad \text { Mean } \pm \text { SD }\end{array}$ & $20.91 \pm 3.5$ & $27.07 \pm 1.35$ & $\mathrm{P}<0.0001$ \\
$\begin{array}{l}\text { Duration of dialysis(months) } \\
\quad \text { Mean } \pm \text { SD }\end{array}$ & $88 \pm 6.4$ & 0 & - \\
$\quad \begin{array}{l}\text { Systolic BP (mmHg) } \\
\text { Mean } \pm \text { SD }\end{array}$ & $148.3 \pm 16.81$ & $115.3 \pm 13.15$ & $\mathrm{P}<0.0001$ \\
$\quad \begin{array}{l}\text { Diastolic BP (mmHg) } \\
\text { Mean } \pm \text { SD }\end{array}$ & $89.3 \pm 9.57$ & $75.75 \pm 8.28$ & $\mathrm{P}<0.0001$ \\
\hline
\end{tabular}

The data were presented as mean $\pm \mathrm{SD} \quad \mathrm{n}=$ number, $\mathrm{NS}=$ non significant

Table (2): Serum levels of markers of chronic inflammation of the studied groups.

\begin{tabular}{l|lll}
\hline \multicolumn{1}{c|}{ Item } & $\begin{array}{l}\text { Group I } \\
(n=44)\end{array}$ & $\begin{array}{l}\text { Group II Controls) } \\
(n=40)\end{array}$ & P-value \\
\hline hs-CRP (mg/L) & $18.01 \pm 8.83$ & $\begin{array}{l}4.816 \pm 2.51 \\
0 \%\end{array}$ & \\
Mean \pm SD & $66.18 \%$ & $0 \% 0001$ \\
Percentage of inflamed $>10 \mathrm{ng} / 1$ & $33.82 \%$ & $100 \%$ & \\
$\begin{array}{l}\text { Percentage of Non inflamed }<10 \mathrm{ng} / 1 \\
\text { Il-6 (pg/mL) }\end{array}$ & $95.09 \pm 47.43$ & $3.36 \pm 1.51$ & $\mathrm{P}<0.0001$ \\
Mean \pm SD & & & \\
\hline
\end{tabular}

Table (3): Serum levels of markers of oxidative stress in the investigated subjects.

\begin{tabular}{|c|c|c|c|}
\hline Item & $\begin{array}{c}\text { Group I } \\
(n=44)\end{array}$ & $\begin{array}{l}\text { Group II (Controls) } \\
(n=40)\end{array}$ & P-value \\
\hline TBARS $(\mu \mathrm{M} / L)$ & & & \\
\hline $\begin{array}{l}\text { Mean } \pm \text { SD } \\
\text { NO }(\boldsymbol{\mu M} / \mathbf{L})\end{array}$ & $4.61 \pm 2.92$ & $1.27 \pm \quad 0.07$ & $\mathrm{P}<0.0001$ \\
\hline $\begin{array}{l}\text { Mean } \pm \text { SD } \\
T P(\mathbf{M} / \mathbf{L})\end{array}$ & $76.26 \pm 15.24$ & $30.92 \pm 12.49$ & $\mathrm{P}<0.0001$ \\
\hline Mean \pm SD & $10.11 \pm 4.86$ & $5.15 \pm 0.37$ & $\mathrm{P}<0.0001$ \\
\hline $\begin{array}{l}\text { TAC }(\mathbf{m M} \text { Trolox Equiv/L) } \\
\text { Mean } \pm \text { SD } \\
\text { OSI }(\%)\end{array}$ & $1.37 \pm 0.4827$ & $1.92 \pm 0.5$ & $\mathrm{P}<0.0001$ \\
\hline Mean \pm SD & $1.2 \pm 0.87$ & $0.43 \pm 0.17$ & $\mathrm{P}<0.0001$ \\
\hline
\end{tabular}

Table (4): Markers of endothelial dysfunction and atherosclerosis of the studied

\begin{tabular}{l|lll} 
groups. & $\begin{array}{l}\text { Group I } \\
(n=44)\end{array}$ & $\begin{array}{c}\text { Group II (Controls) } \\
(n=40)\end{array}$ & P-value \\
\hline Item & & & \\
\hline $\begin{array}{l}\text { Mean CC-IMT (mm) } \\
\text { Mean } \pm \text { SD }\end{array}$ & $0.92 \pm 0.08$ & $0.68 \pm 0.05$ & $\mathrm{P}<0.001$ \\
VICAM-1 (ng/mI) & $1462 \pm 384.5$ & $611.2 \pm 85.2$ & $\mathrm{P}<0.0001$ \\
Mean \pm SD & &
\end{tabular}


Table (5): Methylenetetrahydrofolate reductase (MTHFR) genotyping data

\begin{tabular}{|c|c|c|c|}
\hline Item & $\begin{array}{l}\text { Group I } \\
(n=44)\end{array}$ & $\begin{array}{l}\text { Group II (Controls) } \\
(n=40)\end{array}$ & $\overline{P \text {-value }}$ \\
\hline $\mathbf{C C}$ number & 25 & 24 & NS \\
\hline Percentage $\%$ & $56.82 \%$ & $60 \%$ & \\
\hline CT number & 12 & 11 & NS \\
\hline Percentage \% & $27.27 \%$ & $27.5 \%$ & \\
\hline TT number & 7 & 5 & NS \\
\hline Percentage \% & $15.91 \%$ & $12.5 \%$ & \\
\hline Total & 19 & 16 & \\
\hline $\begin{array}{l}\operatorname{mutation}(\mathbf{C T}+\mathbf{T T}) \\
\text { Percentage \% }\end{array}$ & $43.19 \%$ & $40 \%$ & NS \\
\hline Allele frequency & & & \\
\hline Item & $\begin{array}{l}\text { Group I } \\
(\mathrm{n}=44)\end{array}$ & $\begin{array}{l}\text { Group II (Controls) } \\
(\mathrm{n}=40)\end{array}$ & P-value \\
\hline C frequency & 62 & 59 & NS \\
\hline Percentage $\%$ & $70.45 \%$ & $73.75 \%$ & \\
\hline$T$ frequency & 26 & 21 & NS \\
\hline Percentage $\%$ & $29.54 \%$ & $26.25 \%$ & \\
\hline
\end{tabular}

Table (6): The studied parameters among patients with different genotypes

\begin{tabular}{|c|c|c|c|c|c|c|}
\hline & \multirow{2}{*}{$\begin{array}{l}\text { TT } \\
\text { Genotype } \\
(n=7)\end{array}$} & \multirow{2}{*}{$\begin{array}{l}\text { CT } \\
\text { Genotype } \\
(n=12)\end{array}$} & \multirow{2}{*}{$\begin{array}{l}\text { CC } \\
\text { Genotype } \\
(n=25)\end{array}$} & \multicolumn{3}{|c|}{ P-value } \\
\hline & & & & $\begin{array}{l}\text { TT vs. } \\
\text { CT }\end{array}$ & $\begin{array}{l}\text { TT vs. } \\
\text { CC }\end{array}$ & $\begin{array}{l}\text { CT vs. } \\
\text { CC }\end{array}$ \\
\hline hs-CRP (mg/l) & & & & & & \\
\hline Mean \pm SD & $22.81 \pm 7.03$ & $17.83 \pm 6.08$ & $\begin{array}{l}14.97 \pm 83.7 \\
1\end{array}$ & NS & 0.028 & NS \\
\hline IL-6 (pg/ml) & & & & & & \\
\hline $\begin{array}{l}\text { Mean } \pm \text { SD } \\
\text { VCAM-1 (ng/ml) }\end{array}$ & $123.9 \pm 25.5$ & $99.5 \pm 25.8$ & $81.6 \pm 47.05$ & NS & 0.039 & NS \\
\hline $\begin{array}{l}\text { Mean } \pm \text { SD } \\
\text { CC-IMT (mm) }\end{array}$ & $1663 \pm 540.6$ & $1527 \pm 261.4$ & $1346 \pm 286.1$ & NS & 0.044 & NS \\
\hline $\begin{array}{l}\text { Mean } \pm \text { SD } \\
\text { TBARS }(\boldsymbol{\mu M} / \mathbf{L})\end{array}$ & $0.98 \pm 0.141$ & $0.976 \pm 0.098$ & $0.88 \pm 0.082$ & NS & 0.029 & NS \\
\hline $\begin{array}{l}\text { Mean } \pm \text { SD } \\
\text { NO }(\boldsymbol{\mu M} / \mathbf{L})\end{array}$ & $6.82 \pm 2.58$ & $5.025 \pm 2.063$ & $3.82 \pm 2.33$ & NS & 0.012 & NS \\
\hline $\begin{array}{l}\text { Mean } \pm \text { SD } \\
\mathbf{T P}(\mathbf{m M} / \mathbf{L})\end{array}$ & $82.93 \pm 15.68$ & $70.92 \pm 15.53$ & $77.64 \pm 13.27$ & NS & NS & NS \\
\hline $\begin{array}{l}\text { Mean } \pm \text { SD } \\
\text { TAC (mM Trolox } \\
\text { Equiv/L) }\end{array}$ & $12.65 \pm 4.74$ & $11.7 \pm 3.83$ & $8.635 \pm 4.943$ & NS & NS & NS \\
\hline Mean \pm SD & $\begin{array}{l}1.41 \pm 0.34 \\
2\end{array}$ & $\begin{array}{l}1.291 \pm 0.527 \\
2\end{array}$ & $\begin{array}{ll}1.529 \pm & 0.44\end{array}$ & NS & NS & NS \\
\hline OSI (\%) & & & & & & \\
\hline $\begin{array}{l}\text { Mean } \pm \text { SD } \\
\text { BMI }\left(\mathbf{K g} / \mathbf{m}^{2}\right)\end{array}$ & $1.35 \pm 0.447$ & $1.52 \pm 0.57$ & $1.64 \pm 0.61$ & NS & NS & NS \\
\hline Mean \pm SD & $20.47 \pm 4.1$ & $20.47 \pm 4.1$ & $21.25 \pm 3.01$ & NS & NS & NS \\
\hline
\end{tabular}


Table (7): The studied parameters in patients with mutated and non mutated genes

\begin{tabular}{|c|c|c|c|}
\hline Item & $\begin{array}{l}\text { Mutated cases } \\
(n=19)\end{array}$ & $\begin{array}{l}\text { Non mutated } \\
\text { cases }(n=25)\end{array}$ & $\overline{P \text {-value }}$ \\
\hline hs-CRP (mg/L) & & & \\
\hline Mean $\pm \mathrm{SD}^{\circ}$ & $20.14 \pm 7.06$ & $14.97 \pm 83.71$ & 0.023 \\
\hline IL-6 (pg/mL) & & & \\
\hline Mean $\pm \mathrm{SD}$ & $115.9 \pm 39.26$ & $81.6 \pm 47.05$ & 0.030 \\
\hline VCAM-1 (ng/mL) & & & \\
\hline Mean \pm SD & $1619 \pm 335.1$ & $1346 \pm 286.1$ & 0.002 \\
\hline CC-IMT (mm) & & & \\
\hline Mean \pm SD & $0.976 \pm 0.11$ & $0.88 \pm 0.08$ & 0.014 \\
\hline $\begin{array}{l}\text { TBARS }(\boldsymbol{\mu M} / \mathbf{L}) \\
\text { Mean } \pm \text { SD }\end{array}$ & $5.69 \pm 2.37$ & $3.82 \pm 2.33$ & 0.006 \\
\hline NO $(\boldsymbol{\mu M} / \mathbf{L})$ & & & \\
\hline Mean \pm SD & $75.34 \pm 16.27$ & $77.64 \pm 13.27$ & NS \\
\hline TP $(\mathrm{mM} / \mathbf{L})$ & & & \\
\hline $\begin{array}{l}\text { Mean } \pm \text { SD } \\
\text { TAC }(\mathbf{m M} \text { Trolox Equiv/L) }\end{array}$ & $12.05 \pm 4.09$ & $8.64 \pm 4.94$ & 0.0192 \\
\hline $\begin{array}{l}\text { Mean } \pm \text { SD } \\
\text { OSI }(\%)\end{array}$ & $1.29 \pm \quad 0.53$ & $1.43 \pm \quad 0.45$ & NS \\
\hline $\begin{array}{l}\text { Mean } \pm \text { SD } \\
\text { BMI }\left(\mathbf{K g} / \mathbf{m}^{2}\right)\end{array}$ & $1.52 \pm 0.35$ & $1.64 \pm 0.62$ & NS \\
\hline Mean \pm SD & $20.47 \pm 4.1$ & $21.25 \pm 3.01$ & NS \\
\hline
\end{tabular}

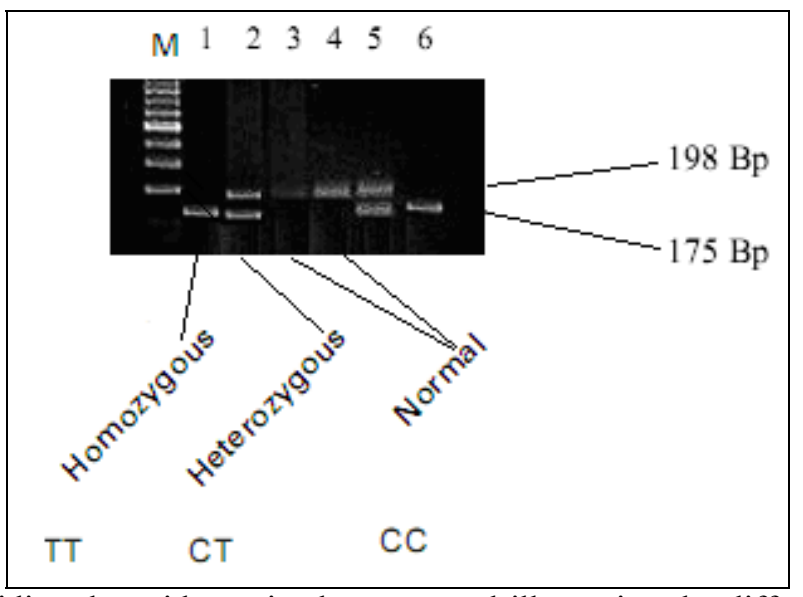

Figure 1: Ethidium bromide- stained agarose gel illustrating the different genotypes of the C667T mutation. The wild type CC shows a single band at the $198 \mathrm{bp}$. The heterozygote CT showed two bands, one at the $198 \mathrm{bp}$ and the second at $175 \mathrm{bp}$, The homozygote TT showed one band at 175. Lane M was 100 bp DNA molecular weight marker. 
Control

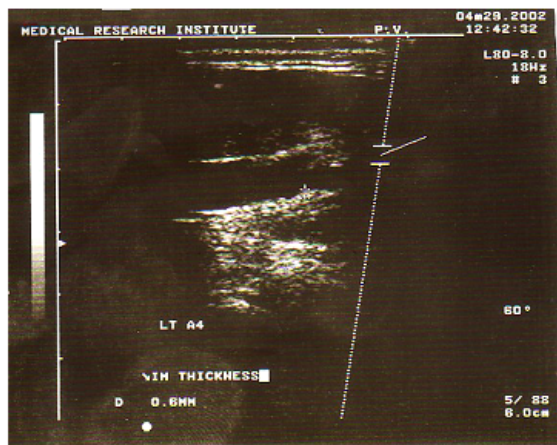

Patient

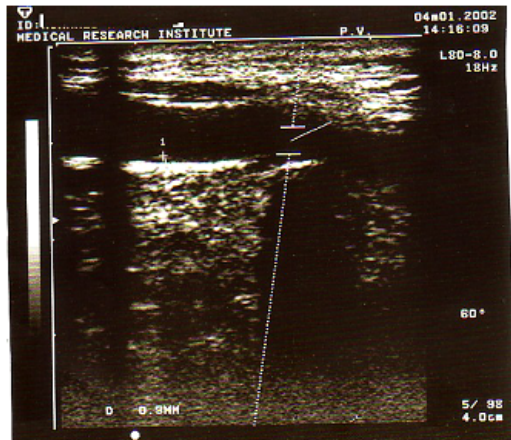

Figure 2: Carotid ultrasonography for measurement of the carotid artery intimal thickness (CC-IMT) in a patient and a control.

\section{DISCUSSION}

Chronic uremia is considered as a pro-inflammatory state associated with high cardiovascular morbidity and mortality ${ }^{\mathbf{( 2 0 )}}$. Serum levels of IL6 and CRP are elevated in pre-dialysis and dialyzed CRF patients ${ }^{\text {(20) }}$. In the current study, the serum levels of hsCRP and IL-6 were elevated as compared with the healthy controls( $\mathrm{p}<0.0001)$ and the percentage of inflamed patients (hs-CRP $>10 \mathrm{ng} / \mathrm{l}$ ) was $66.18 \%$ versus $33.81 \%$ who are not inflamed. This indicates a high prevalence of inflammation in hemodialysis patients as compared with healthy controls. There is a strong positive correlation between the serum levels of IL-6 and CRP as shown in table (8). This finding is in consistence with other studies ${ }^{(21)}$. The inflammatory cytokine "IL-6" stimulates hepatic synthesis of $\mathrm{CRP}^{(21)}$. In the present study, there were positive correlations between the inflammatory markers (CRP and IL-6) and oxidative stress markers (TBARS,
TP and OSI). One of the mechanisms that may account for increased oxidative stress in HD is the chronic inflammation $^{(22)}$. Chronic inflammation, as evidenced by increased levels of the proinflammatory cytokines is a common feature in HD patients. Activation of polymorphonuclear neutrophils and monocytes has been described during $\mathrm{HD}$, which results in the release of reactive oxygen species (ROS) and cytokines $^{(\mathbf{2 3 )}}$. Activated neutrophils generate superoxide anions that combine with endothelial-derived NO, forming highly cytotoxic hydroxyl radical $^{(23)}$. In the present study, there is a positive correlation between inflammatory markers and VCAM-1 and CC-IMT. This is consistent with other studies ${ }^{(21 \& 24)}$. The increase in inflammatory cytokines lead to increased expression of VCAM-1 on the surface of endothelial cells which in turn lead to adhesion of leucocytes and rolling in or transendothelial migration of monocytes into the sub 
endothelium, the early step in the development of atherosclerosis ${ }^{(21,24)}$.

Oxidative stress is a persistent manifestation of ESRD which has been documented by the increase in the oxidative products of fat, carbohydrates, and proteins in tissues and plasma of uremic patients ${ }^{(25)}$. Several etiologic factors for oxidative stress have been proposed in these patients, including uremic reaction of the blood with dialyzer membranes and subsequent contaminating with dialysis byproducts, acute or chronic bacterial infections, ‘ parenteral administration of ferrous sulfate, limitation in consumption of fruits and vegetables that are rich in antioxidant vitamins and natural phytochemicals besides the underlying chronic diseases $^{(25)}$. Furthermore, oxidative stress is responsible for alterations in the composition of lipoproteins that result in oxidation of low-density lipoproteins and the release of shortchain aldehydes, such as malondialdehyde and acceleration of

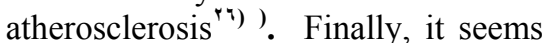
that ROS has a role in the pathophysiology of ischemiareperfusion injury. Due to the impact of ROS on the regulation of cellular cycle, oxygen radicals may cause hypertrophy of the renal tubular cells (27). On the other hand, oxidative stress in ESRD has an important role in the pathogenesis of hypertension, anemia, reduction of erythrocytes lifespan, inflammation, fibrosis, and apoptosis $^{(27)}$.

In the current study, the levels of serum TBARS, NO, TP and OSI were significantly higher in hemodialysis patients as compared with the healthy controls $(p<0.0001)$. Total antioxidant capacity was inversely correlated with TP and OSI. This could be explained by exhaustion of antioxidants set against increased oxidative stress ${ }^{(28)}$.

In the present study, markers of endothelial dysfunction and atherosclerosis CC-IMT and VCAM-1 are significantly higher in hemodialysis group as compared to control group with $\mathrm{P}<0.0001$ for each. The CC-IMT levels were positively correlated with CRP and IL-6 levels as the inflammation is the basic mechanism underlying the pathogenesis of the atherosclerosis (21). Also, CC-IMT levels were positively correlated with VCAM-1 which is essential for the adhesion and sub-endothelial migration of monocyte, the early step in development of atherosclerosis. Also, CC-IMT is positively correlated with the oxidative stress markers (TBARS, NO, TP and OSI) pointing to a role of oxidative stress in the development of atherosclerosis (21,24). So, TBARS, NO and TP could be considered positive determinants and TAC is considered a negative determinant of atherosclerosis.

A higher plasma total homocysteine level is associated with an increased risk of cardiovascular disease in dialysis patients ${ }^{(29)}$. The C677T polymorphism for the gene encoding MTHFR is the most important genetic variant associated with homocysteine metabolism. One study suggested an association between MTHRF gene mutation and plasma homocysteine levels, and atherosclerosis ${ }^{(30)}$. Others did not find such a relationship ${ }^{(31)}$. Lim et al. ${ }^{(32)}$ investigated the association between the MTHFR gene mutation, the 
plasma homocysteine levels and carotid atherosclerosis. They found that, patients bearing the TT genotype had the highest CC-IMT, whereas the lowest CC-IMT values were observed in patients with the $\mathrm{CC}$ genotype. The investigators concluded that both the TT genotype and the $\mathrm{T}$ allele of the MTHFR gene are associated with increased CC-IMT in hemodialysis patients $^{(32)}$. Haviv et al., reported that MTHFR C667T mutation was associated with cardiovascular disease in hemodialysis patients ${ }^{(33)}$.

In the present study, there were no significant difference in the genotyping of MTHFR between patients and controls or in frequency of $\mathrm{C}$ or $\mathrm{T}$ alleles between patients and controls. However, there is a significant difference between the mutated and non mutated patients as regards the inflammatory markers VCAM-1 and CC-IMT. TT genotype is associated with elevated levels of homocysteine which is highly exaggerated in cases of chronic renal failure $^{(34)}$. Hideki et al. ${ }^{(29)}$ reported that in subjects with normal renal function, the TT genotype causes only a $25 \%$ increase in plasma homocysteine compared to subjects with other genotype. Whereas, in patients with ESRD undergoing maintenance dialysis, the TT genotype causes about 40 to $100 \%$ increase in plasma homocysteine, compared to other genotypes who are already have two to three times higher concentrations of homocysteine than normal subjects. The levels of homocysteine are linked with the production of inflammatory markers (35). Homocysteine induced monocyte chemo-attractant protein-1(MCP-1) protein and mRNA levels in macrophage via nuclear factor kappa $\mathrm{B}(\mathrm{NF}-\mathrm{\kappa} \mathrm{B})$ activation, a process found to be mediated by generation of oxidative stress which in turn induce the production of inflammatory cytokines $^{(35)}$.

Homocysteine affects directly the expression of adhesion molecules in endothelial cells and, in particular, VCAM-1 by increasing its gene expression or indirectly by the increase of inflammatory cytokines which in turn increase the expression of adhesion molecules on the surface of endothelial cells. Also, increased oxidative stress is often quoted as a mechanism of homocysteine-induced endothelial cell dysfunction ${ }^{(36)}$. So, homocysteine act as the pro-oxidant and pro-inflammatory ${ }^{(36)}$.

The precise mechanism linking MTHFR mutation with vascular damage is not fully understood. Plasma homocysteine is independently related to aortic stiffness and left-ventricular hypertrophy ${ }^{(37)}$. Homocysteine might cause endothelial injury, endothelial dysfunction, smooth muscle cell proliferation, and an increase in vascular monocyte adhesion ${ }^{(\mathbf{3 8})}$. Also, it induces oxidative stress which plays a critical role in the process of endothelial injury and dysfunction ${ }^{(37)}$. Hyperhomocysteinemia raises the intracellular S-adenosyl-homocysteine (AdoHcy) but not AdoMet (sadenosyl-methionine) concentration. Impairment of methylation reactions increases protein damage. Hypomethylation of DNA can lead to inappropriate gene expression ${ }^{(36)}$. Remethylation and transmethylation rates are significantly lower in 
hemodialysis patients as compared to those in healthy subjects ${ }^{(39)}$.

\section{CONCLUSION}

It could be concluded that there is increased inflammation and oxidative stress in hemodialysis patients as compared to healthy controls. The patients had, also, an increased risk of developing atherosclerosis as indicated by the increase of CC-IMT and VCAM-1 levels.

\section{REFERENCES}

1- Lysaght, M.J. (2002): Maintenance dialysis population dynamics: current trends and long-term implications. J Am Soc Nephrol., 13: 37-40

2- U.S.Renal Data System, USRDS (2007): The reference tables in the second half of the ADR are similar to those of previous editions. Titles have been further clarified, and footnotes provide more information on the patient populations used in the analyses.

3- Kalantar-Zadeh, K. and Kopple, J.; (2001): Relative contributions of nutrition and inflammation to clinical outcome in dialysis patients. AM J Kidney Dis., 38:1343-1350.

4- Akdag, I.; Yilmaz, Y.; Kahvecioglu, S.; Bolca, N.; Ercan, I.; Ersoy, A. and Gullulu, M. (2008): Clinical Value of the MalnutritionInflammation-Atherosclerosis

Syndrome for Long-Term Prediction of Cardiovascular Mortality in Patients with EndStage Renal Disease: A 5-Year-
Prospective-Study. -Nephron Clin Pract., 108:99-105.

5- Stenvinkel, P. Interactions between inflammation, oxidative stress, and endothelial dysfunction in end-stage renal disease. $\mathrm{J}$ Ren Nutr. 13:1444-8.

6- Nurcan, C.; $\quad$ Esra, B.; Nurzen, S.; Pinar, A.; and Mehmet, H. (2008): Oxidative stress in children on hemodialysis: value of autoantibodies against oxidized lowdensity lipoprotein. Pediatric Nephrology 15:114-117.

7- Álvaro, M.; Gonzalo, C.; Arturo, R.; Ana, J. ; Jesús, G.; Alfonso, R.; Maximiliano, R.; and Armando, R. (2008): Human genetic selection on the MTHFR $677 \mathrm{C}>\mathrm{T}$ polymorphism. BMC Med Genet., 9: 104-108 .

8- Burke, G.; Evans, G. and Riley, W.(1995): Arterial wall thickness is associated with prevalent cardiovascular disease in middleaged adults. The Atherosclerosis Risk in Communities (ARIC) Study. Stroke, 26: 386-391.

9- O'Leary, D.; Polak, J. and Kronmal, R. (1999): Cardiovascular Health Study Collaborative Research Group). Carotid-artery intima and media thickness as a risk factor for myocardial infarction and stroke in older adults. N. Engl. J. Med., 340: 14-22.

10- Ekart, R.; Hojs, R.; HojsFabjan, T. and Sheela, $R$. (2005): Predictive value of carotid intima media thickness in hemodialysis patients. Artif Organs., 29: 615-619. 
11- Hojs, R. (2000): Carotid intimamedia thickness and plaques in hemodialysis patients. Artif Organs., 24: 691-695.

12- Allen, M.J.; Myer, B.J.; Khokher, A.M. ;Rushton, N. and Cox, T.M. (1997): Proinflammatory cytokines and the pathogenesis of Gaucher's Disease: increased release of interleukin-6 and interleukin 10. QJM., 90, 19-25.

13- Teitz, N.W. (1995): Clinical guide to laboratory tests, 3rd edition WB Saunders Company, Philadelphia PA, 605-687.

14- Mason, J.C.; Kapahi, P.; Haskard, D.O. (1993): Detection of increased levels of circulating intercellular adhesion molecule 1 in some patients with rheumatoid arthritis but not in patients with systemic lupus erythematosus. Lack of correlation with levels of circulating vascular. Arthritis Rheum, 36(4):519-27.

15- Uchiama, M. and Mihara, M. (1978): Determination of malondialdehyde precursor in tissue by thiobarbituric acid test. Ann. Biochem., 86:271-278.

16- Van Bezooijen, R. L.; Que, I.; Ederveen, A. G. H.; Kloosterhoer, H. J.; Papapoulos, S. E. and Lowik, C. W. (1998): Plasma nitrate + nitrite levels are regulated by ovarian steroids but do not correlate with trabecular bone mineral density in rats. J. Endocrin., 159:27-34.

17- Harma, M.; Capraz, I. and Erel, O. (2005): Measurement of the total antioxidant response in preeclampsia with a novel automated method. Eur J Obstet Gynecol Reprod Biol., 118: 4751.

18- Koracevic, D. ; Koracevic, G.; Djordjevic, V.; Andrejevic, S. and Cosic,V. (2001): Method for the measurement of antioxidant activity in human fluids. J. Clin. Pathol., 54:356-36.

19- Frosst, P.; Blom, J.; Milos, R.; Goyette, P.; Sheppard, A.; Matthews, G.; Boers, H.; den Heijer, M,; Kluijtmans, J.; van den Heuvel, $P$. and Rozen, $R$. (1995): A candidate genetic risk factor for vascular disease: a common mutation in methylenetetrahydrofolate reductase. Nature Genet., 10: 111-113.

20- Panichi, V.; Migliori, M. and De Pietro S, (2002): C-reactive protein and interleukin-6 levels are related to renal function in predialytic chronic renal failure. Nephron, 91:594-600.

21- Stenvinkel, P.; Barany, P.; Heimbu, O.; Pecoits-Filho, R.; and Lindholm, B. (2002): Mortality, malnutrition, and atherosclerosis in ESRD what is the role of interleukin-6? . Kidney International, 61: 103-108.

22- Elisabeth, C.; Samouilidou1; Eirini, J.; Grapsa, I.; Kakavas, A.; and Basilis, A. (2003): Oxidative stress markers and Creactive protein in end-stage renal failure patients on dialysis. International Urology and Nephrology, 35: 393-397.

23- Dursun, B.; Dursun, E.; Suleymanlar, G.; Ozben, B.; Capraz, I.; Apaydin, A. and Ozben, T. (2008): Carotid artery 
intima-media thickness correlates with oxidative stress in chronic hemodialysis patients with accelerated atherosclerosis. Nephrol. Dial. Transplant., 23: 1697-1703.

24- Papagianni, A.; Kalovoulos, M.; kimizis, D.; Vainas, A.; Belechri A; Alexopoulos E and Memmos D. (2003): Carotid atherosclerosis is associated with inflammation and endothelial cell adhesion molecules in chronic hemodialysis patients; Nephrol. Dial. Transplant., 18:113-119.

25- Samadian, F.; LessanPezeshk, M.; Mahdavi-Mazdeh, M.; Kadkhodaie, M.; Sepideh, S. and Ahmadi, F. (2007): Relation of Antioxidants and Acute-Phase Reactants in Patients Receiving Hemodialysis. IJKD ., 1:38-42.

26- Hasselwander, O. and Young, I.S.( 1998): Oxidative stress in chronic renal failure. Free Radic Res., 29:1-11.

27- Vaziri, N.D. (2004): Oxidative stress in uremia: nature ‘ mechanisms, and potential consequences. Semin Nephrol., 24:469-73.

28- Aydın, E.; Fuat, G.; Mehmet, K.; Halil, K.;. Ali, G.; Yıldız, A. and Şahbettin, S. (2006): Oxidative stress, inflammation and early cardiovascular damage in children with chronic renal failure ;Pediatr Nephrol., 21: 545-552

29- Hideki, K.; Fumitake, G. ; Satoru, S. and Ryoichi, M.(2000): The C677T Methylenetetrahydrofolate Reductase Gene Mutation in
Hemodialysis Patients J Am Soc Nephrol., 11:885-893.

30- Inamoto, N.; Katsuya, T.; Kokubo, Y.; Mannami, T.; Asai, T.; Baba, S.; Ogata, J.; Tomoike, H. and Ogihara, T. (2003): Association of methylenetetrahydrofolate reductase gene polymorphism with carotid atherosclerosis depending on smoking status in a Japanese general population. Stroke, 34: 1628-1633.

31- Scaglione, L.; Gambino, R.; Rolfo, E.; Lillaz, E.; Gai, M.; Cassader, M.; Pagano, G. and Cavallo-Perin, P. (2002): Plasma homocysteine, methylenetetrahydrofolate reductase gene polymorphism and carotid intima-media thickness in Italian type 2 diabetic patients. Eur. J. Clin. Invest., 1932: 24-28.

32- Lim, P.; Hung, R. and Wei, Y. (2001): Polymorphism in methylenetetrahydrofolate reductase gene: Its impact on plasma homocysteine levels and carotid atherosclerosis in ESRD patients receiving hemodialysis. Nephron, 87: 249-256.

33- Haviv, Y.S.; Shpichinetsky, V. and Goldschmidt, N. (2002): The common mutations C677T and A1298C in the human methylenetetrahydrofolate reductase gene are associated with hyperhomocysteinemia and cardiovascular disease in hemodialysis patients. Nephron 92: 120-126.

34- Födinger, M.; Mannhalter, C.; Wölfl, C.; Pabinger, I.; Müller, E.; Schmid, R.; Hörl, W.H. and 
Sunder-Plassmann, G. (1997): Mutation (677 $\mathrm{C}$ to $\mathrm{T}$ ) in the methylenetetrahydrofolate

reductase gene aggravates hyperhomocysteinemia in hemodialysis patients. Kidney Int., 52: 517-523.

35- Shastry, S. and James, L.R. (2009): Homocysteine-induced macrophage inflammatory protein-2 production by glomerular mesangial cells is mediated by PI3 Kinase and p38 MAPK. Inflammation: 6:27-34.

36- Carluccio, M.A.; Siculella, L.; Ancora, M.A.; Massaro, M.; Scoditti, E.; Storelli, C.; Visioli, F.; Distante, A. and De Caterina, R. (2003): Olive oil and red wine antioxidant polyphenols inhibit endothelial activation: antiatherogenic properties of Mediterranean diet phytochemicals. Arterioscler.
Thromb. Vasc. Biol., 23: 622629.

37- Walter, H. $\quad$ (2004): Atherosclerosis and uremic retention solutes. Kidney international, 66: 1719-1731.

38- Harpel, P.C.; Chang, V.T. and Borth, W. (1992): Homocysteine and other sulfhydryl compounds enhance the binding of lipoprotein(a) to fibrin: A potential biochemical link between thrombosis atherogenesis and sulfhydryl compound metabolism. Proc. Nat. Acad. Sci. USA., 89:1019310197.

39- Van Guldener, C.; Kulik, W.; Berger, R.; et al. (1999): Homocysteine and methionine metabolism in ESRD: A stable isotope study. Kidney Int., 56: 1064-1071.

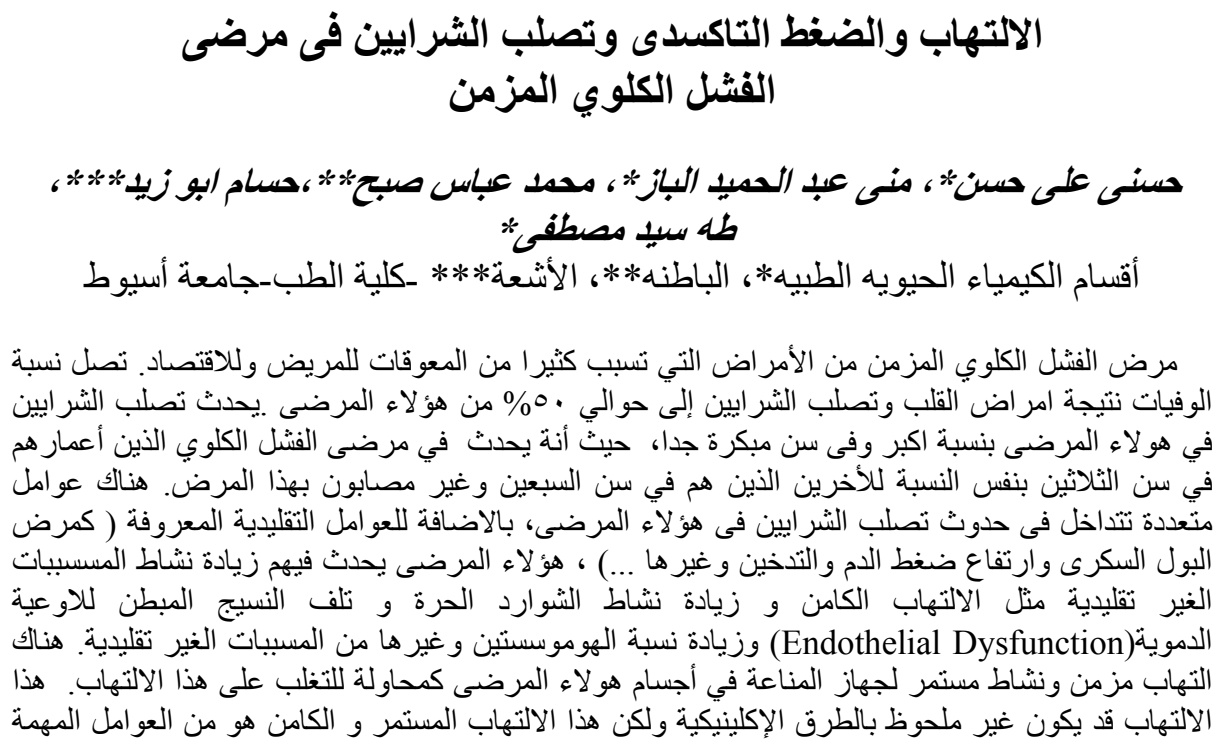




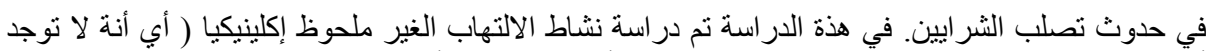

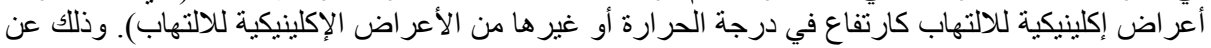

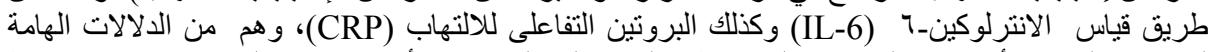

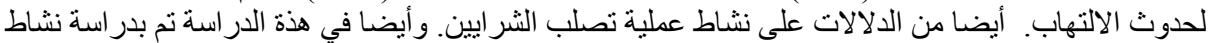

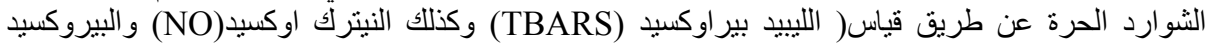

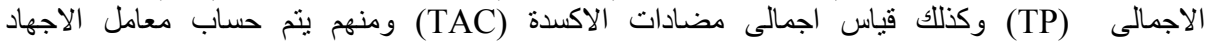

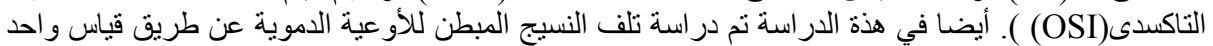

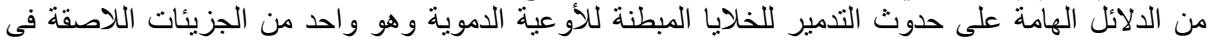

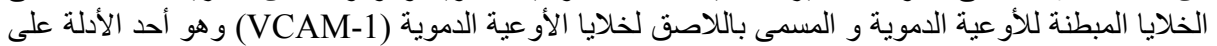

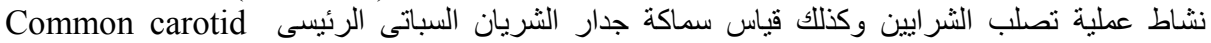

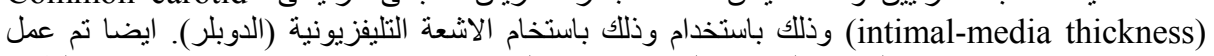

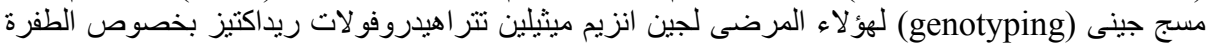

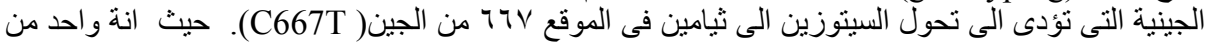

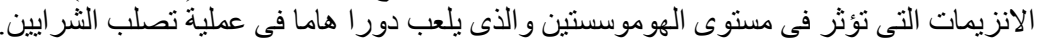

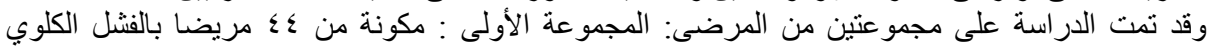

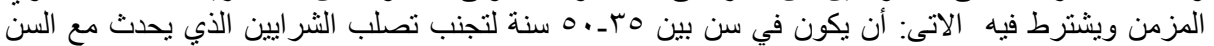

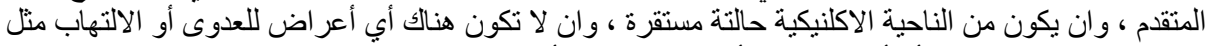

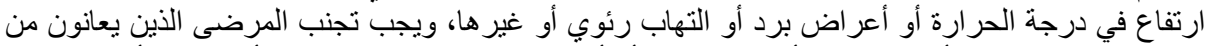

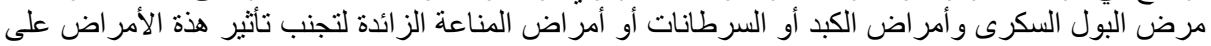

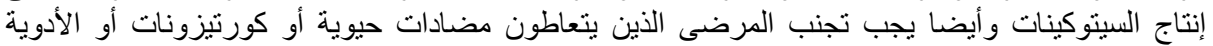

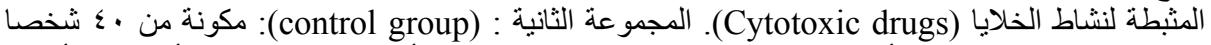

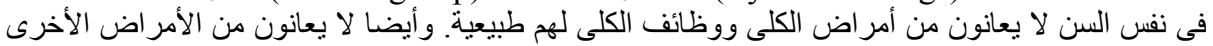

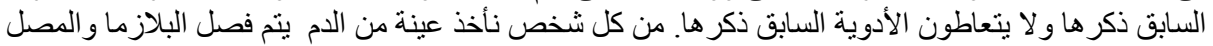

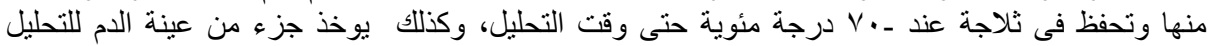

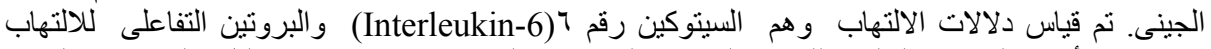

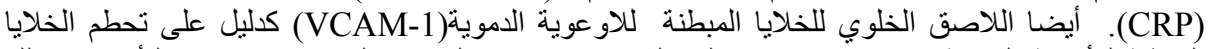

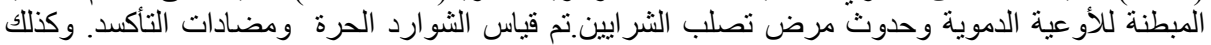

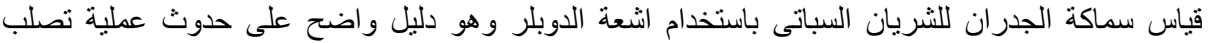

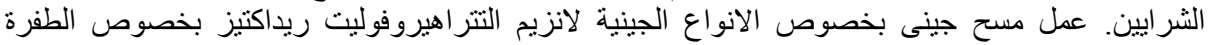

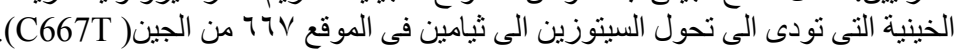

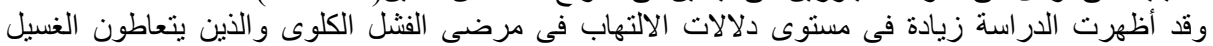

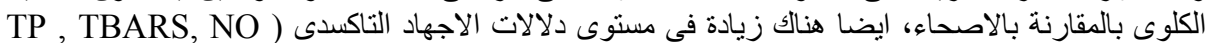

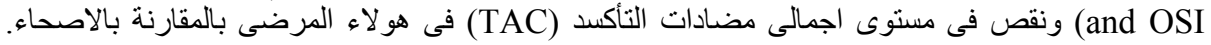

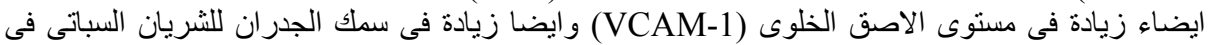

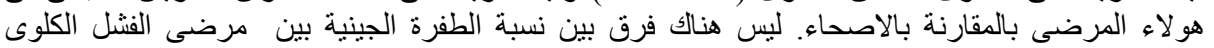

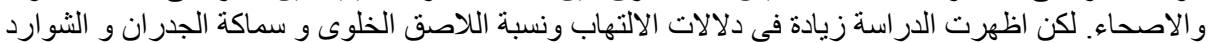

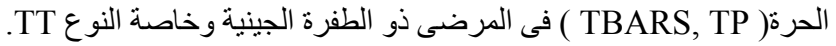

